\title{
Erratum
}

\section{Editorial. Methodology and reporting of meta-analyses in the neurosurgical literature}

To THE READERSHIP: An error occurred during production of the paper "Editorial. Methodology and reporting of meta-analyses in the neurosurgical literature" $(J$ Neurosurg, published online ahead of print on January 24, 2014; DOI: 10.3171/2013.10.JNS13724).

The last paragraph of the editorial should have been the following:

While the quality of meta-analyses in the neurosurgical literature may be improving, at least in the journals Klimo et al. examined, our current standards of peer review still do not adequately address these common defects in design and analysis, and the conclusions of published meta-analyses must be evaluated in the context of these findings. We feel this should apply as well to the many papers in our journals that perform a statistical synthesis on published data but are not self-identified as meta-analyses or even as systematic reviews, a group of papers that is actually much larger than the cohort Klimo et al. have examined. The authors urge a standardization of meta-analyses beginning with a clear definition of what a meta- analysis is, requiring both authors and reviewers to use both the PRISMA and AMSTAR checklists and requiring authors to include experts in the statistical methodology of meta-analysis at the authorship level when undertaking systematic reviews. We agree with the authors that their study has identified a crisis in our literature that our journals should address, before a potentially useful tool loses its value.

Instead, three additional paragraphs were erroneously included after that passage.

We apologize to the authors, John H. Sampson, M.D., Ph.D., and Fred G. Barker II, M.D., as well as to the readership, for the error. We have eliminated the extraneous material at the end of the editorial, the correct version has been posted online as of February 14, 2014, and is printed correctly in this issue.

GiLlian Shasby Director of Publications-Operations Journal of Neurosurgery Publishing Group Charlottesville, VA 